\title{
Study regarding the use of movement games and relays in order to improve primary students' strength qualities
}

\author{
Talaghir Laurentiu-Gabriel ${ }^{1 a}$, Mîndrescu Veronica ${ }^{2}$, and Ion-Ene Mircea ${ }^{1}$ \\ ${ }^{1}$ University Dunarea de Jos",Domneasca Street, no. 46, 800008, Galati, Romania \\ ${ }^{2}$ Transilvania University, Bdul Eroilor, no. 29, 500036, Braşov, Romania
}

\begin{abstract}
The present paper is part of wider research carried out during 2015 - 2016 with primary school students from a primary school in Galati, Romania, which studied the possibility of increasing the motor skill manifestation indices. Within this research we wished to present the role that movement games and relays could play in developing strength as motor skill and we used 6 movement games and 3 relays for this purpose. Movement games were used within physical education classes whose topic was the development of strength as motor skill. Relays were used at the beginning or at the end of the PE classes as a means of engaging the body during exercise. For assessment, we used three specific trials for testing strength as motor quality: crunches, back extension and standing long jump. The results recorded in the final testing for all the trials revealed significant progress as compared to the initial tests. The statistical processing of data was performed with the help of the SPSS 23.0 software. The positive results proved that the use of movement games and relays is efficient for the increase of strength motor skill manifestation indices with primary school students.
\end{abstract}

Keywords: movement games, primary students, motor skill

\section{Introduction}

As in any activities performed by humans, in the education domain, too, there is an ongoing concern to improve methods so that the expected results be achieved in a faster and more efficient manner. Physical education, which is part of the general education process, follows the same guidelines of the structural and conceptual evolutions adapted to social realities and to the students' needs in line with technological progress.

In recent years, in this sense of evolution and adaptation, new curricula for PE for the Romanian primary school system have been drawn up $[13,14]$.

${ }^{\text {a } C o r r e s p o n d i n g ~ a u t h o r: ~ G a b r i e l . T a l a g h i r @ u g a l . r o ~}$ 
This reality of adapting the curricula to the ever changing social reality is reflected in the specialists' concerns worldwide $[5,7,8,9,6]$.

To meet the new conceptual guidelines, an adaptation of the practical activities' content to the general competences, encountered in the new primary school curricula, is required. The evaluation, as part of the instructive-educative process, must be in acord with its finalities. From this point of view it must be in acordance with the trends which are noticed at the international level [12]

Specialists such as $[2,11]$ consider that the physical education class is different from the other classes in terms of content, structure, methodology, dynamics, location and learning particularities. The learning rules are specific. They focus on forming perceptions and motor skills and on acquiring knowledge while practising physical exercise as well as on shaping motor and moral-volitional qualities.

In this context of re-thinking the PE classes, movement games, which are already known to specialists in the domain, acquire new formative and educational meanings, which contribute significantly to the growth and development of children. The game, as an activity for young children, also has an integrative role in the community, being thus in line with the competences that must be developed in primary school students.

School PE has two components, that is practical activity training and education as the assimilation of a set of rules, which regulate human behaviour [3, 4]. The problem of organising the educational process for the primary school PE class in an efficient manner has always been a main concern for specialists of all times. Therefore, specialists proved that, in order to produce lasting and performant results, the quality of the educational process mainly depends on the conscious selection of the training means, methods and procedures [15].

The development of motor qualities in primary school students represents a topical subject because the diversity of the actuating means at young ages can generate positive results in the growth and development process [10]. Also, a high degree of motor skill manifestation, in all its aspects, will determine the student to participate in the proposed activities within classes because he will be able to withstand a sustained effort. Another positive effect, generated by a high manifestation level of the motor skill indices, is the opportunity of acquiring some skills, which are specific to some sports, quicker.

The present paper is the result of the equal contribution of all authors.

\section{Procedure}

The experiment was conducted in the Secondary school no.18, in Galaţi. The length of the experiment was represented by school year 2015-2016. In the experiment, there were 59 primary school students involved, who were in the third grade. Out of these, there were 29 boys and 30 girls.

In order to conduct the experiment under standard research conditions, we established class III A as the experimental group and class III B as the control group.

The aim of the experiment was to notice if, by using movement games, it is possible to improve the strength motor skill manifestation indices in primary school students.

In order to carry out the study within the experimental group, we used 6 movement games and 3 relays for the development of strength as motor quality.

The movement games and the relays were selected in such a way that they could correspond to the students' motor manifestation level and were used in the PE classes during which the development of strength as motor skill was planned in accordance with the planning documents, approved by the school management at the beginning of the school year. 
We didn't interfere in the activities performed by the control group. For the control group, the planning documents drawn up by the PE teacher, and approved by the school management, were taken into account, and the activities regarding the development of motor qualities were performed with the help of specific means. In the case of the control group, the traditional teaching method was adopted for the learning units with specific content.

The data obtained at the initial and final testing of both groups (the experimental and the control group) was interpreted from a statistical point of view by means of a specialised software, named SPSS 23.0.

In order to create diversity within the PE classes, these games and relays were coded and combined. The content of the lessons was made up of two movement games and one relay or one movement game and two relays. The relays were also used at the beginning and at the end of the class and during classes whose subject was not the development of strength as motor quality, as means of engaging in effort.

For assessment, we used three trials which are to be found in the National School Assessment System for the Physical Education class [1]. They were: crunches, back extension and standing long jump.

The description of the trials is as follows:

- for the "crunches" trial, the student laid on his/her back, with the hands behind the head, with the legs bent and the soles on the ground, supported by a colleague, and he/she lifted the torso to a vertical position and, then, the student returned to the initial position; the number of repetitions was recorded.

- for the "back extensions" trial, the student laid on his/her abdomen, face down, with the hands behind the head, the feet being supported by a colleague, and he/she lifted the torso towards the vertical position so that his/her head was higher than the height of the gymnastics bench and, then, the student returned to the initial position; the number of repetitions was recorded.

- for the "standing long jump" trial, the student stood with his feet slightly apart, with the arms up, behind a line, and he/she took off and landed using both feet, swinging the arms and bending the knees to provide forward drive. The distance from the line to the heel was measured.

The trials were taken at the beginning and at the end of the school year.

\section{Results and discussions}

In order to decide if the movement games proposed by us within the experiment had the expected effects on primary school students, the data collected during the initial and final tests were statistically interpreted.

The statistical analysis was performed within the group and between the groups for each of the three trials in which the students participated.

In table no.1, we presented the results obtained by the control group and by the experimental group in the "crunches" trial.

Table 1. Results in the "crunches" trial

\begin{tabular}{|c|c|c|c|c|c|c|c|c|}
\hline \multirow{2}{*}{} & \multicolumn{3}{|c|}{ The control group(n=15) } & \multicolumn{4}{c|}{ The experimental group(n=14) } \\
\cline { 2 - 9 } & $\begin{array}{c}\text { T.I. } \\
\overline{\mathrm{X}} \pm m\end{array}$ & $\begin{array}{c}\text { T.F. } \\
\overline{\mathrm{X}} \pm m\end{array}$ & $\mathrm{t}$ & $\mathrm{p}$ & $\begin{array}{c}\text { T.I. } \\
\overline{\mathrm{X}} \pm m\end{array}$ & $\begin{array}{c}\text { T.F. } \\
\overline{\mathrm{X}} \pm m\end{array}$ & $\mathrm{t}$ & $\mathrm{p}$ \\
\hline Boys & $6,73 \pm 1,10$ & $8,33 \pm 0,90$ & $-7,48$ & $<.000$ & $6,79 \pm 1,18$ & $9,50 \pm 1,01$ & $-13,98$ & $<.000$ \\
\hline Girls & $4,79 \pm 0,69$ & $6,71 \pm 10,72$ & $-7,23$ & $<.000$ & $4,69 \pm 0,70$ & $7,25 \pm 0,93$ & $-16,29$ & $<.000$ \\
\hline
\end{tabular}


It may be noticed that in the initial test, the control group and the experimental group obtained similar results, which indicated a similar level of physical training. The groups of boys had an average result value of 6.73 repetitions, the control group, and of 6.79 repetitions, the experimental group. In the final test we may notice that both groups of boys obtained better results and the recorded progress may be considered to be significant ( $\mathrm{p}$ $0,001)$.

In table no. 1 we may also notice the result evolution for the groups of girls. The girls had initial average performance values of 4.79 repetitions, in the case of the control group, and 4.69 repetitions in the case of the experimental group, fact which indicated a similar value of the groups for this age level. In the final test, both group of girls obtained average performance levels higher than in the initial tests $(p<0,001)$. This demonstrates the fact that the activity performed during PE classes is efficient and leads to an increase in the motor skill manifestation indices, by using various methods.

The statistical analysis performed between groups we may notice significant differences both for the group of girls and for the group of boys. The statistical interpretation is presented in table no.2.

Table 2. The statistical analysis between the control groups and the experimental groups for the "crunches" trial

\begin{tabular}{|c|c|c|c|c|}
\hline & $\begin{array}{c}\text { G.M (n=15) } \\
\overline{\mathrm{X}} \pm m\end{array}$ & $\begin{array}{c}\text { G.E }(\mathbf{n}=\mathbf{1 4}) \\
\overline{\mathrm{X}} \pm m\end{array}$ & $\mathrm{t}$ & $\mathrm{p}$ \\
\hline Boys & $8,33 \pm 0,90$ & $9,50 \pm 1,01$ & $-3,27$ & $<.003$ \\
\hline Girls & $6,71 \pm 10,72$ & $7,25 \pm 0,93$ & $-1,76$ & $<.088$ \\
\hline
\end{tabular}

As shown for the "crunches" trial, all the groups involved in the research recorded positive evolutions in terms of performance, which are considered significant from a statistical point of view. In table no. 2 we may notice the fact that both the girls' and the boys' experimental groups had a superior evolution as compared to the control groups. This fact is due to the significant statistically proven progress, $(p<0,003)$ for the boys' experimental group and $(\mathrm{p}<0,088)$ for the girls' experimental group. By highlighting these results, we can assert that the methods proposed by us within the experimental groups were efficient and led to an increase in the strength motor skill manifestation indices.

Further on in the statistical analysis, we wanted to see the evolution of the results recorded in the "back extensions" trial. These results are presented in table no. 3.

Table 3. Results in the "back extension" trial

\begin{tabular}{|c|c|c|c|c|c|c|c|c|}
\hline & \multicolumn{4}{|c|}{ The control group $(\mathbf{n}=\mathbf{1 5})$} & \multicolumn{4}{|c|}{ The experimental group $(\mathbf{n}=\mathbf{1 4})$} \\
\hline & $\begin{array}{c}\text { T.I. } \\
\overline{\mathrm{X}} \pm m\end{array}$ & $\begin{array}{c}\text { T.F. } \\
\overline{\mathrm{X}} \pm m\end{array}$ & $\mathrm{t}$ & $\mathrm{p}$ & $\begin{array}{c}\text { T.I. } \\
\overline{\mathrm{X}} \pm m\end{array}$ & $\begin{array}{c}\text { T.F. } \\
\overline{\mathrm{X}} \pm m\end{array}$ & $\mathrm{t}$ & $\mathrm{p}$ \\
\hline Boys & $7,87 \pm 0,74$ & $10,07 \pm 0,96$ & $-8,40$ & $<.000$ & $7,86 \pm 1,23$ & $11,29 \pm 1,43$ & $-24,98$ & $<.000$ \\
\hline Girls & $6,21 \pm 1,25$ & $7,93 \pm 1,20$ & $-10,49$ & $<.000$ & $6,31 \pm 1,13$ & $9,13 \pm 1,02$ & $-12,35$ & $<.000$ \\
\hline
\end{tabular}

In order to render a unitary character to the research, we used the same type of statistical analysis for the analysis both within and between groups. The statistical analysis carried out between groups focused on the results obtained in the final tests between the control groups and the experimental groups.

From table no. 3 we may notice that the average values obtained by the groups involved in the research in the initial tests showed a similar level of physical training. The boys' control group recorded an average value of 7.87 repetitions, whereas the experimental group recorded a result of 7.86 repetitions. In the case of the group of girls, the control 
group had an average performance value of 6.21 repetitions, whereas the experimental group recorded an average performance level of 6.31 repetitions.

In the final tests for this trial we can assert that all the groups of boys and girls involved in the research recorded significant progress. This is because, from a statistical point of view, by analysing the data within the groups, the indicator $\mathrm{p}$ was established as having a highly significant value $(\mathrm{p}<0,001)$.

As a result, we continued the analysis from a statistical point of view between the boys' and the girls' control and experimental groups.

The results are presented in table no. 4 .

Table 4. The statistical analysis between the control and the experimental groups for the "back extensions" trial

\begin{tabular}{|c|c|c|c|c|}
\hline & $\begin{array}{c}\text { G.M (n=15) } \\
\overline{\mathrm{X}} \pm m\end{array}$ & $\begin{array}{c}\text { G.E }(\mathbf{n = 1 4 )} \\
\overline{\mathrm{X}} \pm m\end{array}$ & $\mathrm{t}$ & $\mathrm{p}$ \\
\hline Boys & $10,07 \pm 0,96$ & $11,29 \pm 1,43$ & $-2,70$ & $<.012$ \\
\hline Girls & $7,93 \pm 1,20$ & $9,13 \pm 1,02$ & $-2,63$ & $<.013$ \\
\hline
\end{tabular}

As we may notice from the table above, the results recorded in the final tests by the experimental groups are superior to those recorded by the control groups. Thus, the experimental group of boys obtained an average performance value in the final test in the "back extensions" trial of 11.29 repetitions. This result is significant from a statistical point of view because $p<0,012$. As far as the girls' experimental group is concerned, it obtained an average performance value of 9.13 repetitions. This result is superior to the one recorded by the girls' control group (7.93 repetitions). The achieved progress is a positive one because it is significant form a statistical point of view $(p<0,013)$.

The third trial used as assessment for the primary school students involved in the research was the "standing long jump", whose aim was to establish the improvement level of strength as motor quality at the leg level. The results for this test are synthetically presented in table no. 5. After tabulation, the results were also statistically interpreted.

Table 5. The results in the "standing long jump" trial

\begin{tabular}{|c|c|c|c|c|c|c|c|c|}
\hline \multirow{2}{*}{} & \multicolumn{4}{|c|}{ The control group(n=15) } & \multicolumn{3}{c|}{ The experimental group(n=14) } \\
\cline { 2 - 9 } & $\begin{array}{c}\text { T.I. } \\
\overline{\mathrm{X}} \pm m\end{array}$ & $\begin{array}{c}\text { T.F. } \\
\overline{\mathrm{x}} \pm m\end{array}$ & $\mathrm{t}$ & $\mathrm{p}$ & $\begin{array}{c}\text { T.I. } \\
\overline{\mathrm{x}} \pm m\end{array}$ & $\begin{array}{c}\text { T.F. } \\
\overline{\mathrm{x}} \pm m\end{array}$ & $\mathrm{t}$ & $\mathrm{p}$ \\
\hline Boys & $1,05 \pm 10,03$ & $1,14 \pm 0,03$ & $-7,10$ & $<.000$ & $1,07 \pm 0,04$ & $1,20 \pm 0,04$ & $-11,75$ & $<.000$ \\
\hline Girls & $1,01 \pm 0,03$ & $1,11 \pm 0,03$ & $-8,85$ & $<.000$ & $1,00 \pm 0,03$ & $1,15 \pm 0,01$ & $-30,02$ & $<.000$ \\
\hline
\end{tabular}

In table no. 5 we may notice that, as with the other trials included in the research, the results recorded in the "standing long jump" trial, in the initial tests, by all the groups, were similar.

Significant differences were noticed within the final tests as compared to the initial tests. The boys' control group obtained an average performance level of 1.14 metres. This result led to a significant progress from a statistical point of view because $(p<0,001)$. The experimental group of boys obtained in the final test an average performance level of 1.20 metres, which, as compared to the value of the initial test, of 1.07, is considered to be highly significant from a statistical point of view $(p<0,001)$.

The girls' control group obtained in the final test an average performance value of 1.11 metres. In this case, too, the progress achieved was considered highly significant $(p<0,001)$ as compared to the results recorded in the initial test. The experimental group of girls obtained in the final test an average performance level of 1.15 metres. The progress 
achieved was considered to be highly significant $(\mathrm{p}<0,001)$ as compared to the average value of the performance obtained in the initial test, of 1 metre.

The statistical analysis performed within the groups helped in revealing the fact that all the groups had positive evolutions in the final test as compared to the initial test. This shows that the practice of physical exercise in an organised manner, within the mandatory PE classes, has a positive effect on the improvement of the strength motor skill manifestation indices.

In order to see if the proposed movement games and relays significantly influenced the results obtained in the "standing ling jump", we performed a statistical analysis on the results obtained by the groups involved in the final tests. These results are presented in table no. 6 .

Table 6. The statistical analysis between the control and experimental groups for the "Standing long jump" trial

\begin{tabular}{|c|c|c|c|c|}
\hline & $\begin{array}{c}\text { G.M (n=15) } \\
\overline{\mathrm{X}} \pm m\end{array}$ & $\begin{array}{c}\text { G.E }(\mathbf{n}=\mathbf{1 4}) \\
\overline{\mathrm{X}} \pm m\end{array}$ & $\mathrm{t}$ & $\mathrm{P}$ \\
\hline Boys & $1,14 \pm 0,03$ & $1,20 \pm 0,04$ & $-4,31$ & $<.000$ \\
\hline Girls & $1,11 \pm 0,03$ & $1,15 \pm 0,01$ & $-3,97$ & $<.000$ \\
\hline
\end{tabular}

The boys' experimental group recorded a performance of 1.20 metres in the final test, which is superior to that recorded by the control group (1.14 metres). This positive result is also significant from a statistical point of view $(p<0,001)$.

The girls' experimental group obtained an average performance value in the final test of 1.15 metres. This result showed significant progress within the group as compared to the initial test. Also, it is considered superior to the result recorded by the control group (1.11 metres) in terms of statistical analysis because the value of the significance threshold indicates this fact $(\mathrm{p}<0,001)$.

\section{Conclusions}

As a result of the analytical presentation of all the results obtained by the third grade students in the trials included in the research, we can draw several conclusions. The main conclusion is that the use of movement games and relays has a positive effect on the possibilities to influence the strength motor quality manifestation indices.

In conjunction with the requirements stipulated in the general competences that must be developed in primary school students, we can assert that this game-like PE class meets the new conceptual requirements from the PE curriculum.

The use of movement games and relays created a better dynamics during the PE class, thus achieving the competences proposed for this age group by integrating the students' motor skill manifestation.

We consider that movement games and relays used as practice within PE classes represent a method by means of which, on the one hand, the student enjoys the activities proposed and, on the other hand, he/she can independently play the same games and relays in different other groups. Therefore, the students will come to enjoy movement and this, in its turn, will determine the student to independently practise physical exercise as a means of maintaining health.

From the point of view of the performance-related assessment, we may assert that the idea of enjoying sports activities and their integrative role is diminished. We consider that, at the primary school level, at least, different criteria and assessment tests should be drawn up in order to evaluate students' activities that do not focus on competitiveness and on the perception of physical exercise as a means of achieving performance. 
The attitudinal aspects, the integration of students in a group, the ability to communicate by using terms from the motor activity domain are only a few benefits brought by movement games and relays in students' evolution.

\section{References}

1. C. Filip et all., The National Assessment and Examination Department, The National School Assessment System for the PE class.Bucuresti: MNE, (1999)

2. D. Stojiljkovic, D. Pirsl, Impacts of specific exercising on motor abilities development in junior elementary schoolchildren, Acta Kinesiologica, 10 (2), 60-64 (2016)

3. G. Griggs, (Ed.), An Introduction to Primary Physical education, 151-161, (2012)

4. J. L. Currie, Teaching Physical Education in Primary School - An integrated health perspective, Publisher: ACER Press, 112-118 (2013)

5. J. MacLean, R. Mulholland, S. Gray, A. Horrell, Enabling curriculum change in physical education: the interplay between policy constructors and practitioners, Physical Education and Sport Pedagogy, 20(1), 79-96 (2015)

6. M. Jess, N. Carse, J. Keay, The primary physical education curriculum process: more complex that you might think!!, Education 3-13 International Journal of Primary, Elementary and Early Years Education, 44(5), 502-512 (2016)

7. M. O'Sullivan, New directions, new questions: relationships between curriculum, pedagogy, and assessment in physical education,, Sport Education and Society, Vol. 18(1), 1-5 (2013)

8. N. Carse, Primary teachers as physical education curriculum change agents, European Physical Education Review, 21(3), 309-324, (2015)

9. P. Vlcek, Discourse on curriculum development in physical education, recent development in Europe, 9th International Conference on Sport and Quality of Life, 335-343, (2013)

10. T. Buszard, R Machar, S. W. Masters Rich, et all, Scaling Tennis Racquets During PE in Primary School to Enhance Motor Skill Acquisition Research Quarterly for Exercise and Sport, 87(4), p. 414-420, (2016)

11. T. M. Iconomescu, Didactics of Physical Education and Sport - Course notes, Zigotto Publishing house, Galati, (2013)

12. T. M. Iconomescu,.., D. I. Alexe., Differences and similarities in curriculum and assessment in physical education in eastern european states, Journal „Analele Universităţii Ovidius Constanţa. Serie Physical Education and Sport - Science, Movement and Health, XV(1), 41- 46, (2015)

13. The Ministry of National Education, Curriculum for Physical Education, The preparatory grade, the first grade and the second grade, Bucureşti, (2013)

14. The Ministry of National Education, Curriculum for Physical Education, The third grade and the fourth grade, Bucureşti, (2013)

15. T. M. Iconomescu, L. G. Talaghir, Teaching approach to enhance motor skills for students in primary school, Procedia - Social and Behavioural Sciences, 152, 746-751, (2014) 